\title{
Article
}

\section{A Photo Based Measurement System using a Measuring Camera}

\author{
Masayoshi Takahashi*1, Kazuhiko Saito*1, Norihiko Shiraishi*2, To- \\ shiro Iehara*1 and Fumitoshi Takahashi*1
}

\begin{abstract}
In 1993, Minolta Camera Co., Ltd. produced a special camera , MC-100, as a prototype. It can record the size of the object that it focuses on and the distance between the camera and the object. Using this and other instruments, we developed a photo based measurement system for measuring trees. We measured diameter and tree height and the results showed that the accuracy of this system is good enough for survey or study usage. The advantages of this system are 1) it is possible to measure indirectly, 2) it is possible to measure and record at the same time and the record has a lot of information other than the measurement value, 3) it is simple and easy to operate and can be used by one person. The disadvantages are 1) it is not cost effective because each measurement requires a photos, 2) it is very hard to measure in dark conditions. However, this system has potential for general measurement of stands and forests.
\end{abstract}

Keyword:diameter measurement, height measurement, measuring camera, forest mensuration system, forest inventory

\section{INTRODUCTION}

Although many instruments have been developed for measuring a tree and/or forests, it is still necessary to develop a new measurement instrument with high accuracy which is easy and quick to use.

In 1993, Minolta Camera Co., Ltd. produced a special camera , MC -100 , as a prototype (Fig. 1). It can record the size of the object that it focuses on and the distance between the camera and the object. Thus, only taking a photo, it can measure indirectly without any target or mirror. In addition, provides a visual record as well as the measurement value. SANO et al.(1995) use a measuring camera to measure trees and found that it was useful for measuring seedlings or defects in trees such as length of

*1 Forest Management Division, Forestry and Forest Products Research Institute, P.O. Box16, Tsukuba Norin Kenkyu Danchi-nai, Ibaraki, 305, Japan

*2 Hokkaido Research Center, Forestry and Forest Products Research Institute, 7 Hitsujigaoka, Toyohira-ku, Sapporo, Hokkaido, 062 , Japan scratch marks and widths of frost cracks. However, it was difficult to measure tree height with a measuring camera because of the limits in the range of measurement and measurement accuracy.

We combined this camera together with an angle sensor, an image scanner and a computer to produce a new photo based measuring system for forest inventory.

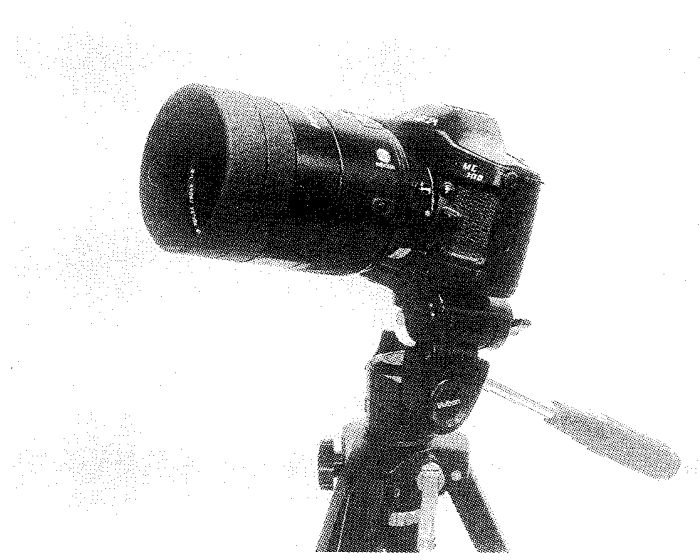

Fig. 1 The measuring camera MC-100 
This paper describes the method and accuracy of our new measurement system. First, the details of our system, including its basic method of measurement, are presented. Then we examine its accuracy and method to correct systematic errors in both diameter and height measurements of trees. In the last section, the capabilities of this system are discussed.

\section{COMPONENTS OF THE SYSTEM}

The system is composed of 4 devices (Fig. 2), which are the measuring camera, $\mathrm{MC}-100$, an angle sensor, a color image scanner and measurement software for a personal computer.

First, we take a photo of the measurement object with $\mathrm{MC}-100$. At the same time, we record the angle of eleva- tion using an angle fitted to the camera. MC-100 is a special camera made by Minolta Camera Co. Ltd. based on an auto focus camera. Operations of this camera are basically same as other AF camera. Measurements can be made with MC-100 using 4 types of exclusive lenses (Table $1)$.

MC-100 has two modes for measurement, scale and distance mode (Fig. 3). In distance mode, it can measure the distance from the lens to the object in focus. When the

Table 1 Exclusive lenses for MC-100

\begin{tabular}{|c|c|}
\hline Name of Exclusive Lens & Range of measurement \\
\hline $50 \mathrm{~mm}$ macro $\mathrm{F} 2.8$ & $0.2-1 \mathrm{~m}$ \\
\hline $100 \mathrm{~mm}$ macro $\mathrm{F} 2.8$ & $0.4-2 \mathrm{~m}$ \\
\hline $500 \mathrm{~mm}$ reflex $\mathrm{F} 8$ & $4-99 m$ \\
\hline $35-200 \mathrm{~mm}$ zoom F4.5-5.6 & $1-15 \mathrm{~m}$ \\
\hline
\end{tabular}

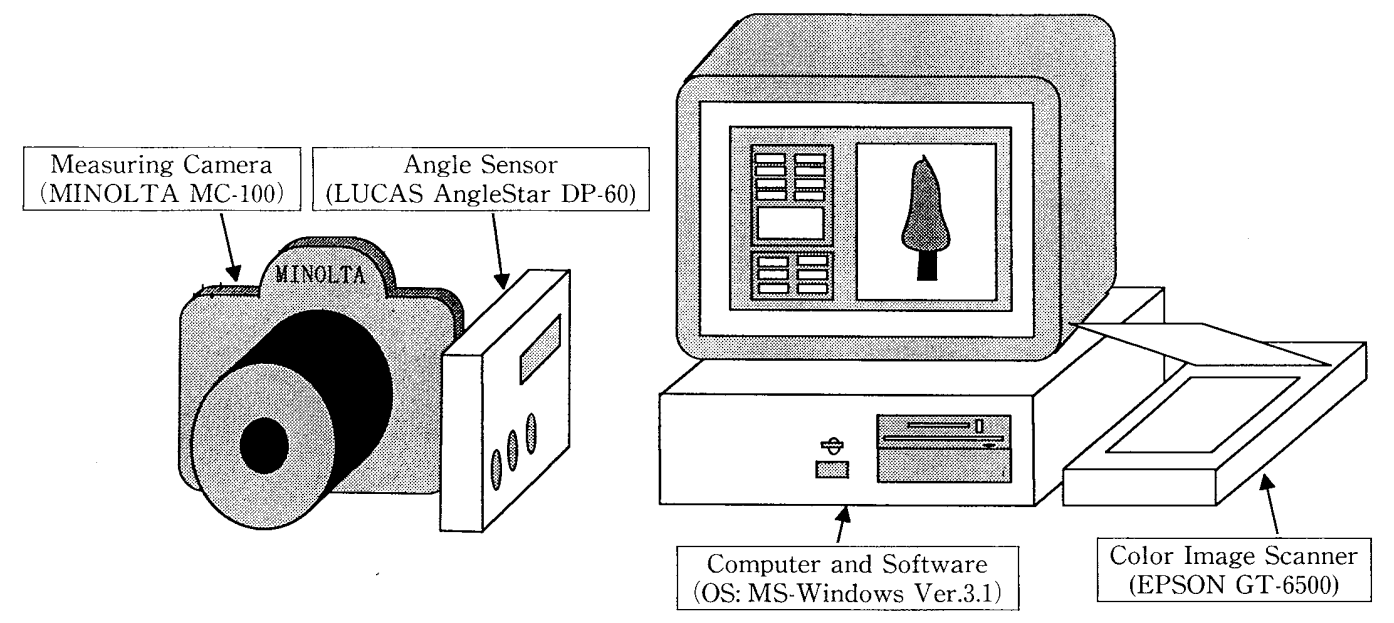

Fig. 2 The components of the system

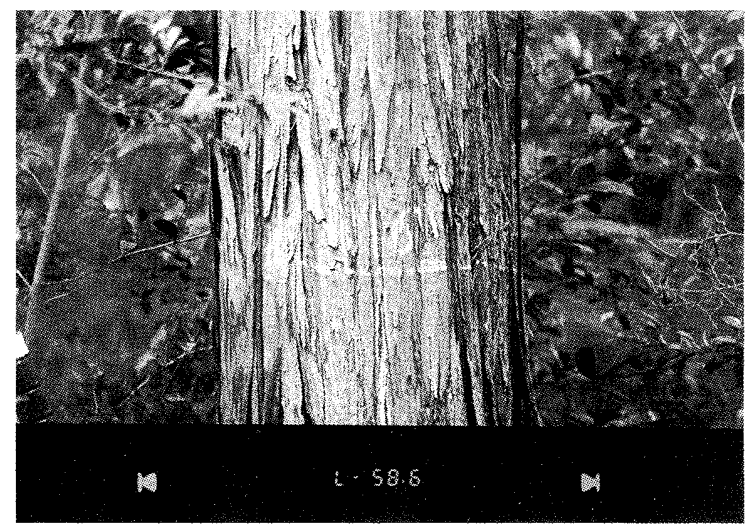

Scale mode

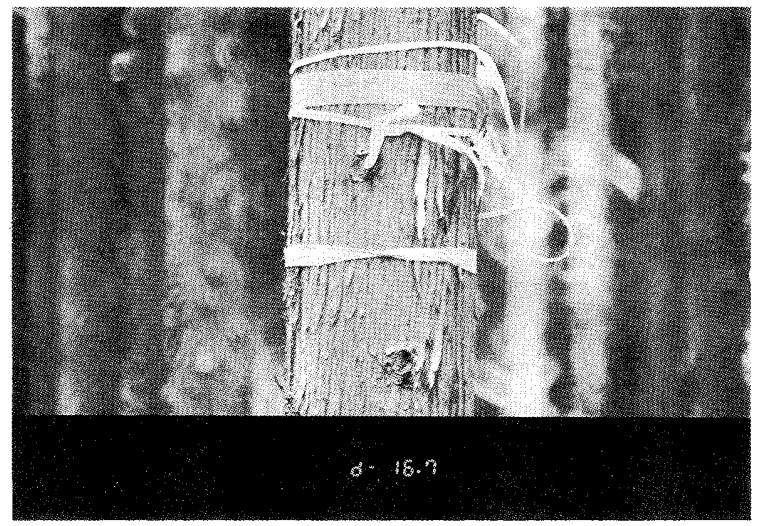

Distance mode

Fig. 3 Photographs taken by the measuring camera 
distance from an object to the lens is " $a$ ", the focal length value is " $f$ ", and the extension value is " $x$ ", then

$$
\frac{1}{a}+\frac{1}{(f+x)}=\frac{1}{f}
$$

We can calculate the distance from the object to the lens by

$$
a=(f+x) \frac{f}{x}
$$

The relationship between the length of the object " $L$ " and the length " $l$ " on the film is

$$
\frac{L}{\mathrm{l}}=\frac{a}{(f+x)}
$$

Substituting (1) for (2) then the size of the object can be calculated as

$$
L=\frac{f l}{x}
$$

The camera can also display a numerical value in the view finder and display panel. The focal lens value " $f$ " is reported from the lens to the camera and the extension value " $x$ " is calculated from the AF drive encoder output. The relationship between the value of AF drive encoder output and the extension value " $x$ " is not linear and is automatically corrected by the camera. Some additional ideas have been devised for improving its accuracy.

In scale mode, the part of object to be measured must be fitted to the scale mark on the view finder. If this cannot be done, it is possible to calculate the size of the object by proportional allotment using the scale mark.
The photographs are measured using software we developed. Photo images are entered into the computer, using a color image scanner. The software runs on MSWindows. The operations can be done mainly by dragging or clicking a mouse. If needed, measurement values can be corrected automatically by the software.

\section{THE ACCURACY AND CORRECTING METHOD OF THE MEASUREMENT}

The Accuracy of Diameter Measurement

We measured diameters after taking the photos by calculating the object size from the scale mark using proportional allotment. To evaluate its accuracy, we tested diameter measurements in 2 ways.

First we evaluated the basic accuracy of the camera by measuring cylindrical objects of regular shape in a room. We tested the camera with a $500 \mathrm{~mm}$ lens using 4 objects of differing diameters; $10.7,15.6,20.7$ and 31.9 $\mathrm{cm}$. The distances varied from about $4 \mathrm{~m}$ to $40 \mathrm{~m}$ and the angle of elevation was 0 . Fig. 4 shows the distribution of the errors from 112 measurements. The average error was

$-1.7 \mathrm{~mm}$ and the standard deviation was $4.4 \mathrm{~mm}$. The variance of errors became larger with measuring distances, but there was no significant relationship between error and
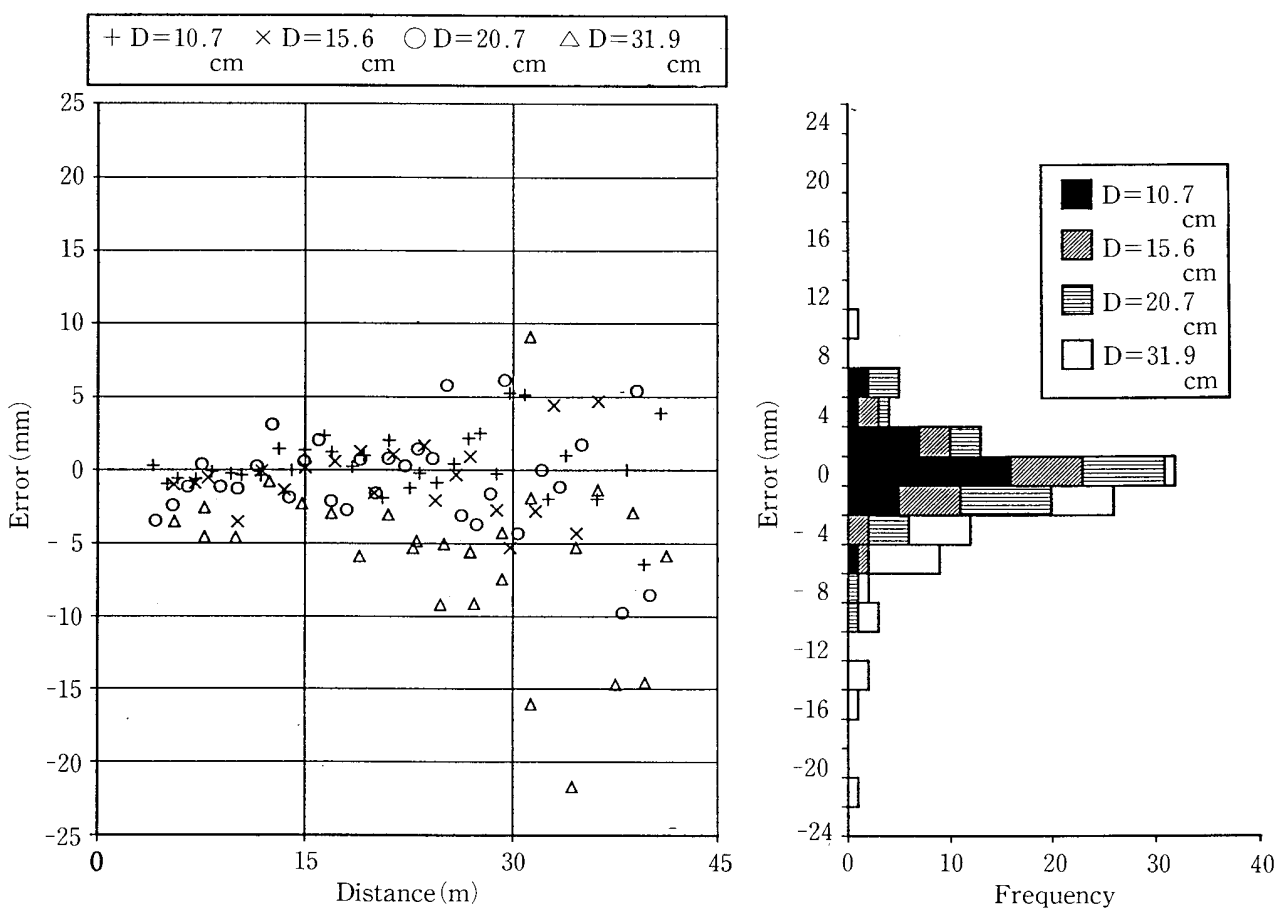

Fig. 4 Distribution of errors in the measurement of the diameters of 4 objects of known size 
diameter. Some measurements especially those for the 31.9 $\mathrm{cm}$ object had large errors. We think this was because the edges of the objects were unclear in the poor light conditions.

Measurements of this kind can contain 2 kinds of systematic error (SHIRAISHI 1995; SaITo et al. 1995). One is overestimation. When we take a picture (Fig. 5), we can' $\mathrm{t}$ see the real diameter-ends $\mathrm{B}$ and $\mathrm{C}$ from the viewpoint $\mathrm{A}$, and we identify $\mathrm{G}$ and $\mathrm{H}$ as the diameter-edges. The other

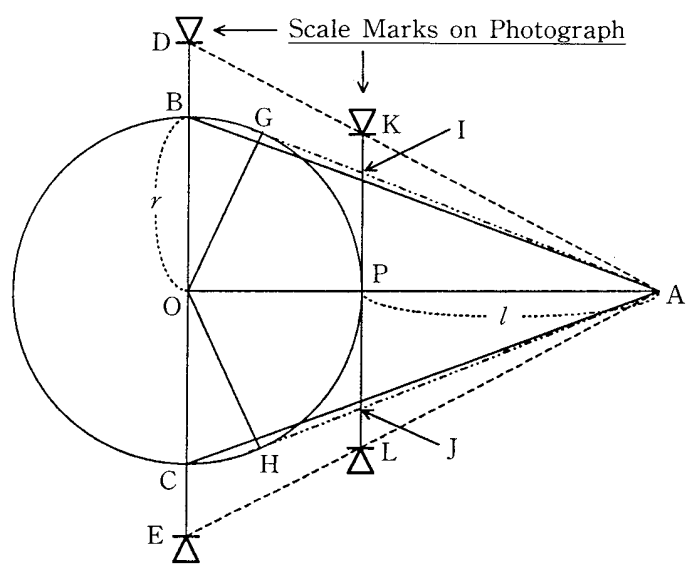

Fig. 5 Cross-section of a stem as viewed by a measuring camera type of systematic error is an underestimation. When we take a picture, the camera focuses on $\mathrm{P}$ and identify $\mathrm{IJ}$ as the diameter. The actual diameter is $\mathrm{BC}$, but smaller IJ is measured. This error can be corrected using this expres. sion.

$$
B C=2 r=\frac{I J^{2}+I J \sqrt{I J^{2}+(2 l)^{2}}}{2 l}
$$

The distribution of errors after correction is shown in Fig. 6. At first, the measurement errors were biased negatively. After correction, they became normally or slightly positive for near distance. The average error became -0.3 $\mathrm{mm}$ and the standard deviation was $4.3 \mathrm{~mm}$.

According to the specifications of the camera, the standard measurement error is $2 \%$ for near distances and 5 $\%$ for farther distances. Our results were within this range.

Then we applied it to two actual tree measurements. Test site 1 was a 35-year-old hinoki (Chamaecyparis obtusa) plantation in Tsukuba Experimental Forest. We took 29 measurements at $1.2 \mathrm{~m}$ height using the $500 \mathrm{~mm}$ lens at variable distances from about $10 \mathrm{~m}$ to $30 \mathrm{~m}$. Fig. 7 shows the measurement errors excluding the systematic errors. The average error was $+6.6 \mathrm{~mm}$ and standard deviation was $4.4 \mathrm{~mm}$ The distribution of the errors show an obvious positive bias. In this case, we have to consider the effect of detached bark. When we used a caliper for diameter measurements, it was pressed against the stem. Thus there was a significant difference between the ordinal caliper measurement and the measurement using this sys-
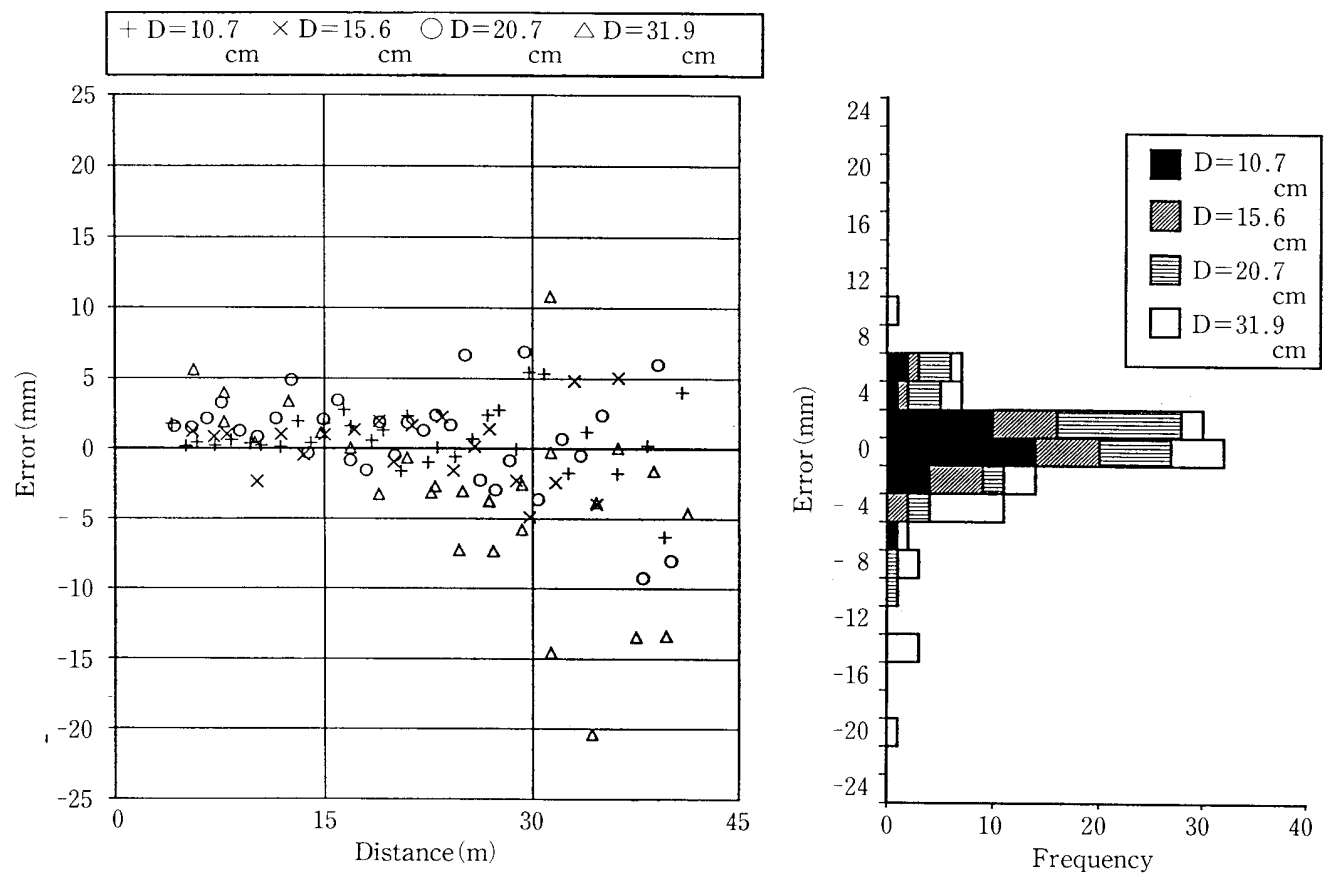

Fig. 6 Distribution of diameter measurement errors after correction for systematic errors 

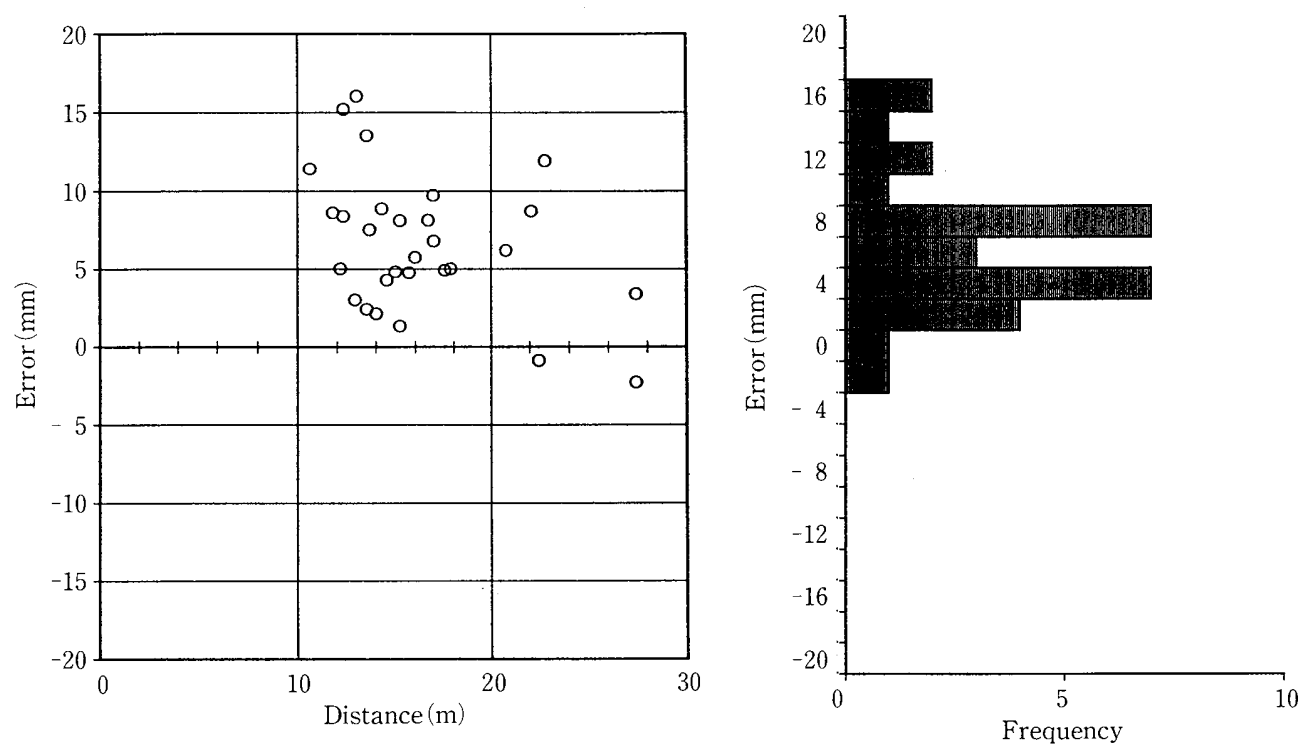

Fig. 7 Distribution of diameter measurement errors in test site 1

tem. Fig. 8 shows the distribution of the thickness of he detached bark. Fig. 9 shows the distribution of measurement errors excluding systematic errors and the effect of detached bark. The mean was $+1.6 \mathrm{~mm}$ and standard deviation was $4.6 \mathrm{~mm}$ Once again that the standard measurement error of the camera became grater as the distance to the object increased.

Test site 2 was a 31-35-year-old sugi (Cryptomeria japonica) plantation in the Former Forest Breading Center's Test Field. Using the $500 \mathrm{~mm}$ lens, we took diameter measurements at the $1.2,3.2$ and $5.2 \mathrm{~m}$ above ground. The measuring distance varied between about $15 \mathrm{~m}$ and $24 \mathrm{~m}$ and the diameters ranged between about $13 \mathrm{~cm}$ and $35 \mathrm{~cm}$ We compared the camera measurements with field measurements obtained with caliper. Fig. 10 shows the measurement errors after correction for the systematic errors and the effect of bark. Mean error was $+0.15 \mathrm{~mm}$ and standard deviation was $0.49 \mathrm{~mm}$ There was no significant relationship between measurement error and its height.

\section{The Accuracy of Tree Height Measurement}

Two methods were devised for measuring tree heights. Method 1 was to calculate height by trigonometry using angle data from the angle sensor and distance data from the measuring camera. When the angle of the tree top is $\alpha$, the angle of the tree bottom is $\beta$, and the distance is $D$ with elevation $\gamma$, we can calculate tree height $H$ as

$$
H=D \cos \gamma(\tan \alpha+\tan \beta)
$$

Method 2 was to calculate height from a photograph including a stick of known length and the tree, using proportional allotment. Tree height is calculated as

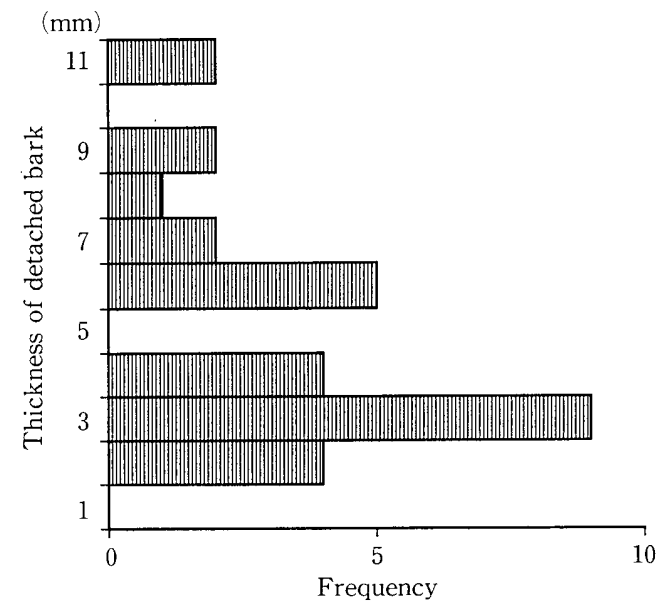

Fig. 8 Distribution of the thickness of detached bark

$$
H=L \frac{(X 1-X 3)}{(P 1-P 2)}
$$

where $L$ is the length of the stick and $X 1, X 3, P 1$ and $P 2$ are as shown in Fig. 11. There are relationships between $X, Y$ and the $f$ value of the lens, $f$, as shown below.

$$
\begin{aligned}
& \frac{X}{f}=\frac{\sin \theta_{1}}{\sin \left(\pi-\theta_{1}\right)} \\
& \frac{Y}{X}=\frac{\sin \theta_{3}}{\sin \theta_{4}}
\end{aligned}
$$

Where $\theta_{1}, \theta_{2}, \theta_{3}$ and $\theta_{4}$ are shown by Fig. 11. Further,

$$
\begin{aligned}
& \theta_{3}=\frac{\pi}{2}-\theta_{1} \\
& \theta_{4}=\frac{\pi}{2}+\theta_{1}-\theta_{2}
\end{aligned}
$$



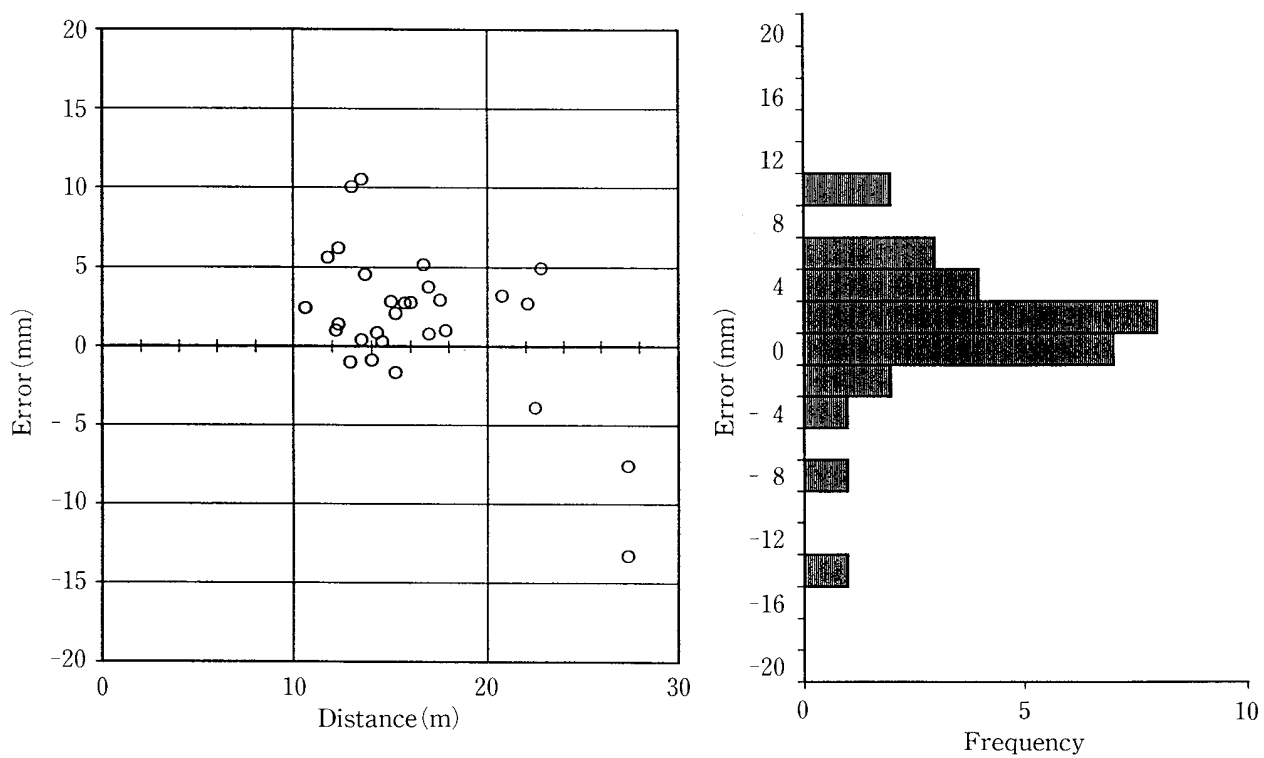

Fig. 9 Distribution of diameter measurement after correction of systematic errors in test site 1
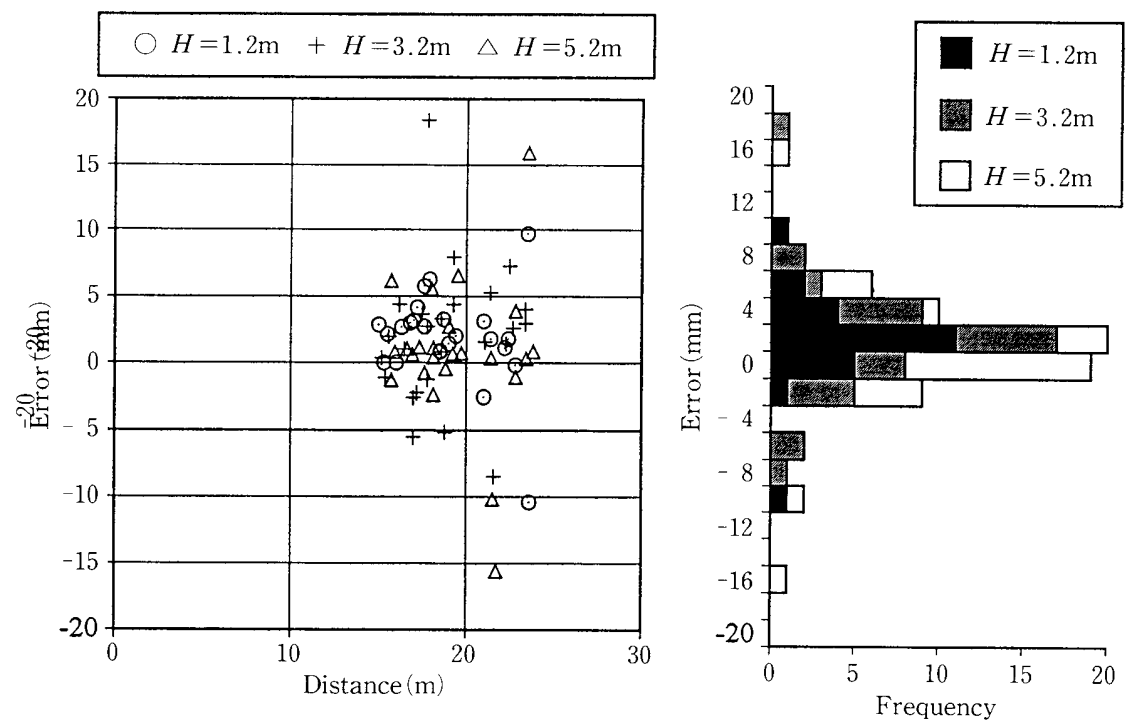

Fig. 10 Distribution of diameter measurement after correction of systematic errors in test site 2

so

$$
\begin{aligned}
& \frac{x}{f}=\frac{\sin \theta_{1}}{\cos \left(\theta_{2}-\theta_{1}\right)} \\
& \frac{Y}{X}=\frac{\cos \left(\theta_{2}-\theta_{1}\right)}{\cos \theta_{1}}
\end{aligned}
$$

From expression (1),(6) and (7), we can calculate a tree height by the expression

$$
X=\frac{f y}{\left(f \cos \theta_{2}+y \sin \theta_{2}\right)}
$$

In practice, after entering the photo image in to a computer, we measured the length from the center of a photograph to $X 1, X 3, P 1$ and $P 2$ on the display using measurement software. Tree height was automatically calculated from expression (3) and (8) by the software. We tested both methods and evaluated their accuracy.

First, we applied Method 1 to measure 31-35-year-old sugi (Cryptomeria japonica) plantation stands in the former arboretum of the Forest Tree Breeding Institute using a 500 


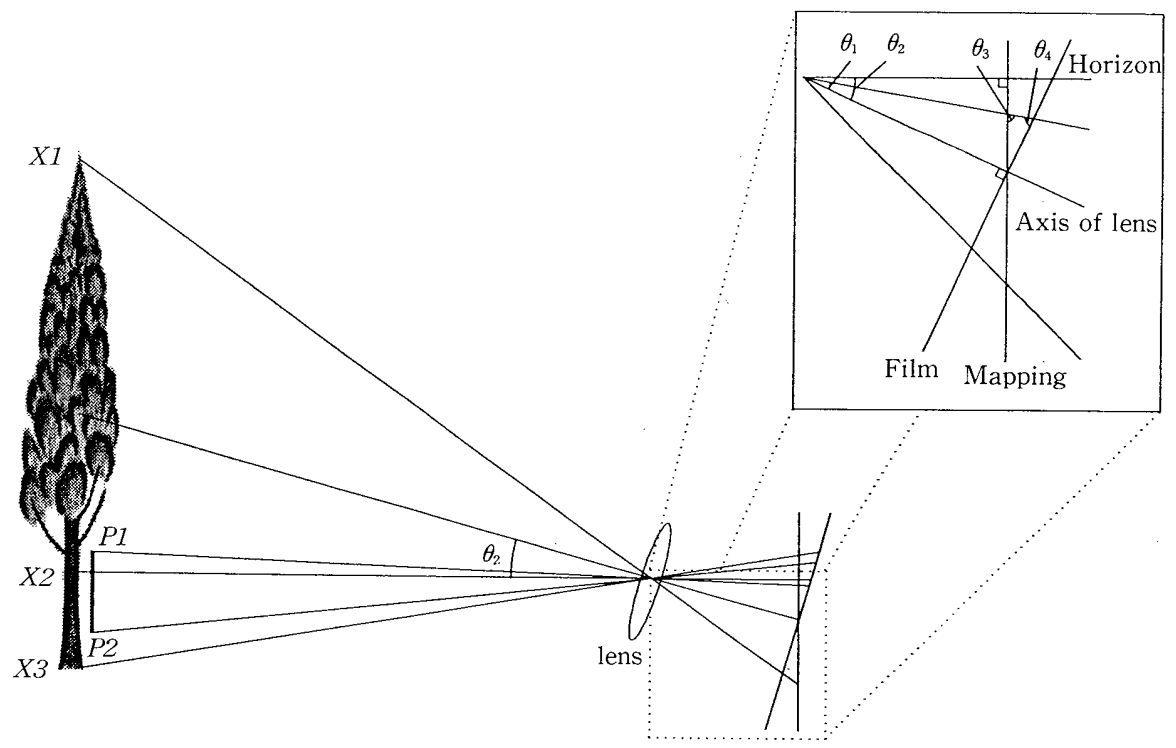

Fig. 11 Vertical-section of a stem as viewed by a measuring camera

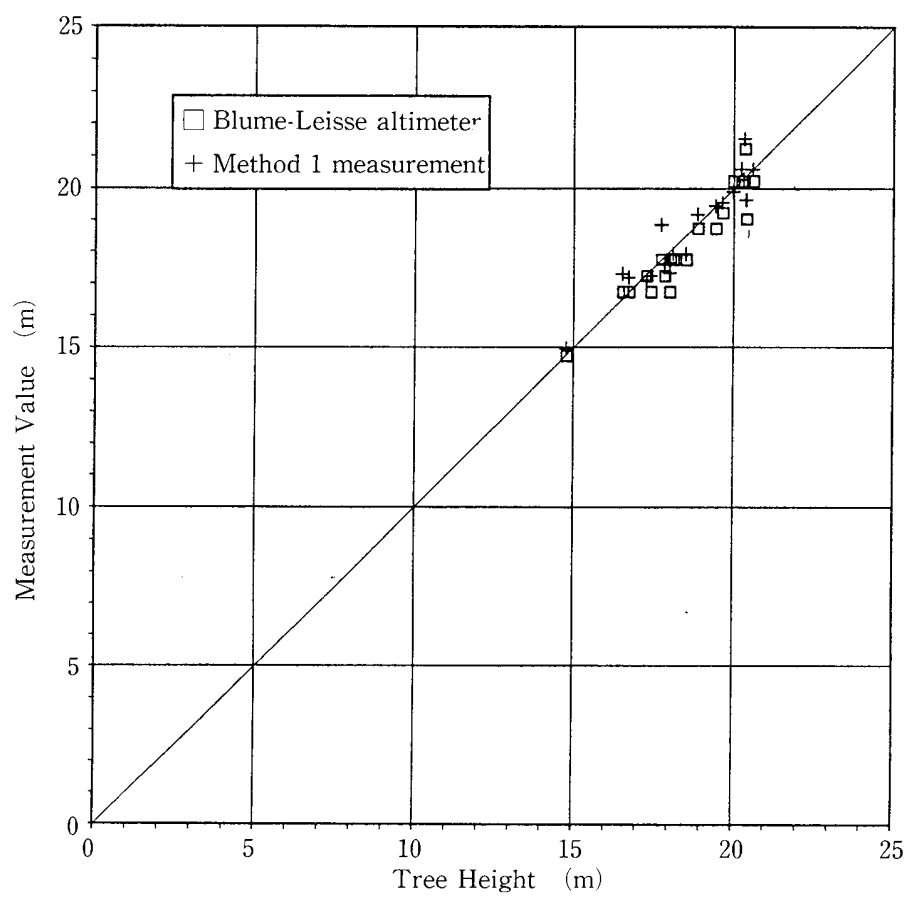

Fig. 12 Distribution of height measurement errors from Method 1

mm lens. For comparison, we also measured tree heights by Blume-leiss altimeter. Afterwards the trees were felled and their real height measured.

Fig. 12 shows the result of 20 measurements. The average errors were $+0.25 \mathrm{~m}(1.26 \%)$ using Method 1 and $-0.33 \mathrm{~m}(-1.89 \%)$ by Blume-leiss altimeter. Standard devi- ation was $0.62 \mathrm{~m}$ for Method 1 and $0.52 \mathrm{~m}$ for Blume-leiss altimeter.

We used Method 2 to measure trees in the arboretum of the Forestry and Forest Products Research Institute using a 35-200 zoom lens. Since it was impossible to fell the trees, we measured the real height with a laser instrument. 


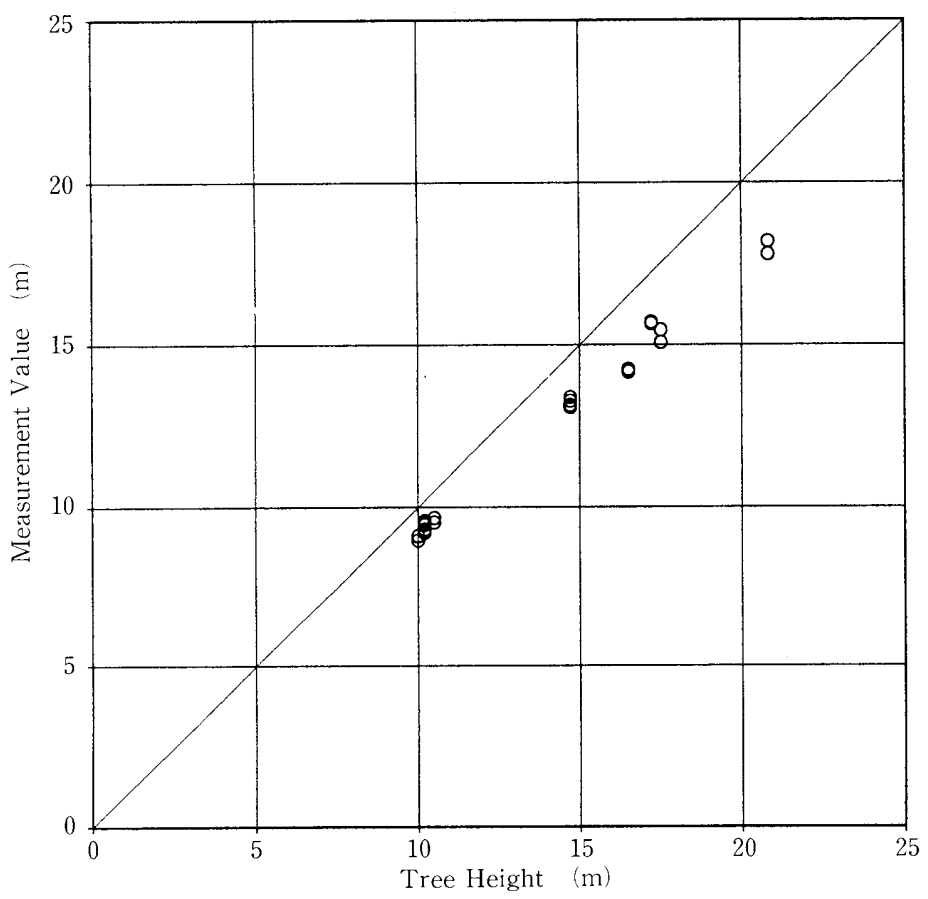

Fig. 13 Distribution of height measurement errors from Method 2

The result of 26 measurements are shown in Fig. 13. The average error was $-1.4 \mathrm{~m}(-10.25 \%)$ and standard deviation was $0.68 \mathrm{~m}$.

\section{DISCUSSION AND CONCLUSIONS}

The results of the diameter measurements show that it is possible to measure diameter with sufficient accuracy, although the results include the effect of bark and there is a slight positive bias. When we compared the results of measurement using caliper and this system, the latter must be adjusted to remove the effect of detached bark. SHIRAI SHI (1995) used a measuring camera to measure tree diameters and pointed out its potential for measuring upper diameters. From our test of its accuracy, we conclude that this is possible even by one person with a little practice. In addition, measurement software that we developed make it easy to calculate and error correction of the raw measurement data.

Height measurement using Method 1 showed that it is possible to measure height with similar accuracy to other techniques. Results have a slight positive bias because of the poor definition of the scale mark on the photograph and mechanical errors. Combining Method 1 height measurement and diameter measurement, it is possible to measure upper-diameters at any height.

Height measurement by Method 2 was not accurate enough for routine measurement. The low accuracy may be due to distortion of the lens, halation, poor definition of the stick, or poor light conditions for the photograph, but we cannot be certain of the exact cause from our examinations. The amount of error is likely to depend on the conditions at measurement. However, the field work for Method 2 is quite simple and requires only a short time. Therefore, it could be useful for pre-surveys, where lower accuracy is acceptable. The techniques used for Method 2 could also be applied to other measurements such as crown length, width and shape. In addition, the analysis of the measurement data is simple and easy by measurement software.

The advantages of this system are 1 ) it is possible to measure indirectly, 2) it is possible to measure and record at the same time and the record has a lot of information other than measurement value, 3) operations are simple and easy and it is possible to measure by one person. The disadvantages are 1) it is not cost effective because each measurement requires a photograph, 2) it is very hard to measure in dark conditions. With further improvements, this system has great potential for the general measurement of stands and forests.

\section{ACKNOWLEDGMENT}

This system was developed with CHUO Electronics Co., Ltd. as a joint research project. The 2nd Laboratory, Forest Tree Breeding Institute, especially Mr. Yoshitake 
FujISAWA, and the Wood Quality Laboratory, Forestry and Forest Products Research Institute, especially Dr. Yasuhiko HIRAKAWA, gave us an opportunity to use their test field and height measurement data. Mr. NAKAI, R\&D General Planning Division, Minolta Co., Ltd. gave us a lot of technical advice about the Measuring Camera. The authors appreciate their generous support.

\section{LITERATURE CITED}

Rikimaru, A., (1994): A measuring camera with auto-focus technology.* Journal of the Japan Society of Photogrammetry and Remote sensing: 33 (4):32-34 (in Japanese)
Saito, S., Takailasin, M., Shiraishi, N., Iemara, T. and Takahashi, F (1995) :Tree height and diameter measurements system using a measuring camera. Proceedings of the symposium on forest inven tory and monitoring in East Asia. Japan society of forest planning press. $69-76$

Sano,M., Inose,M. and Ishibashi, S.,(1995) : Examples of measuring trees by using MEASURING CAMERA (MC-100). Trans. Mtg. Hokkaido Br. Jap. For. Soc.43:90-93 (in Japanese)

Shiraishi, N.,(1995) : Upper-stem diameter measurements using a measuring camera. J. Jpn. For. Soc.77:260-262

*The title is a tentative translation from original Japanese title by the authors of this paper.

(Received 3 July 1996) (Accepted 23 October 1996) 